\title{
Atitude empreendedora nas empresas
}

DOI: 10.47224/revista master.v6i11.106

\author{
Danilo Faria de Moura \\ Emanuel Soares Ponciano \\ Eduardo Oliveira Arruda \\ Cristiano Venancio da Silva Filho \\ Luana Moreira Lopes \\ Paolla Angel do Brasil \\ Victor Amadeus de Moraes Gomes \\ Victor Hugo Siqueira da Silva
}

e-mail: danilofmoura@yahoo.com.br

\section{Resumo}

Empreender é o sonho de muitas pessoas e observa-se que grande parte das vezes, o que lhes falta é atitude, esse artigo tem como objetivo orientar sobre a importância da atitude empreendedora fora e dentro das empresas, pontuando como a falta dela pode acarretar perdas de oportunidades e frustrações. Com base em estudos gerados por Chiavenato, Menezes e Dornelas conclui-se que para reduzir os obstáculos e riscos no empreendimento é necessário o incentivo e conhecimento. Ao decorrer desse artigo abordamos o tema por meio da utilização do Arco de Charles Maguerez, seguindo as etapas de observação da realidade, pontos-chave, teorização, hipótese de solução e aplicação na realidade. A aplicação à realidade não se fez possível em virtude da pandemia da COVID-19. Conclui-se que através de cursos oferecidos por instituições como o SEBRAE é possível absorver informações e conhecimentos necessários para iniciar um empreendimento.

Palavras-chave: Empreendedorismo; Home Office; Empreendedorismo Corporativo.

\begin{abstract}
Entrepreneurship is the dream of many people and it is observed that most of the time, what they lack is attitude, this article aims to guide about the importance of the entrepreneurial attitude outside and inside companies, pointing out how the lack of it can result in missed opportunities and frustrations. Based on studies generated by Chiavenato, Menezes and Dornelas it is concluded that in order to reduce obstacles and risks in the enterprise, encouragement and knowledge are necessary. Throughout this article, we approached the theme through the use of the Arco de Charles de Maguerez, following the steps of observing reality, key points, theorizing, hypothesis of solution and application in reality. The application to reality was not possible due to the COVID-19 pandemic. It is concluded that through courses offered by institutions such as SEBRAE it is possible to absorb information and knowledge necessary to start an enterprise.
\end{abstract}

Keywords: $\quad$ Entrepreneurship; Entrepreneurial Attitude; Intrapreneurship.

\section{INTRODUÇÃO}

Segundo Chiavenato, sobre a abertura do seu próprio negócio

Você deve estar profundamente comprometido com ela, para ir em frente, enfrentar todas as dificuldades que normalmente aparecem e derrubar os obstáculos que certamente não faltarão. Se o negócio falhar - e esse é um risco que realmente existe - , isso não deve derrubar seu orgulho pessoal nem sacrificar seus bens pessoais. Tudo deve ser bem pensado e ponderado para garantir o máximo de sucesso e o mínimo de dores de cabeça. CHIAVENATO (2012).

Grande parte das pessoas trabalham em áreas que não eram o que de fato elas sonharam, ou até 
mesmo ter sua própria empresa e deixar de "trabalha para os outros". Na maioria das vezes, o que mais acontece é a pessoa já estar estabilizada em seu trabalho, com um excelente salário, e por alguns fatores não conseguem largar tudo para trás e viver seu sonho. No decorrer deste artigo será explorado sobre o tema e será contemplada uma solução para essa situação.

O presente artigo é resultante de atividades orientadas desenvolvidas no Curso de Administração. A estruturação da pesquisa se deu por meio da Metodologia da Problematização com o Arco de Maguerez e foi vivenciada tendo como marco norteador a seguinte temática: nunca é tarde para ter atitude na vida profissional.

Longenecker em seus estudos sobre empreendedorismo descreve que:

O empreendedor é a pessoa que inicia e/ou dinamiza um negócio para realizar uma ideia ou projeto pessoal assumindo riscos e responsabilidades e inovando continuamente. Essa definição envolve não apenas os fundadores de empresas e criadores de novos negócios, mas também os membros da segunda ou terceira geração de empresas familiares e os gerentes-proprietários que compram empresas já existentes de seus fundadores. LONGENECKER (1998)

Gartner (1990) colabora com essa visão apontando que "o espírito empreendedor está também presente em todas as pessoas que - mesmo sem fundar uma empresa ou iniciar seus próprios negócios - estão preocupadas e focadas em assumir riscos e inovar continuamente mesmo que não estejam em seus próprios negócios."

Diante das possibilidades sinalizadas a confecção desse artigo baseou-se na observação do comportamento de colaboradores das empresas da cidade de Araguari, posteriormente identificadas a bibliografia de aprofundamento sobre a temática e apresentação de hipóteses de soluções que possam contribuir para intervenção social.

Tem-se objetivo geral identificar o potencial da atitude empreendedora nas empresas em prol de melhores resultados. Fazem-se como objetivos específicos compreender a ausências das habilidades intraempreendedoras no contexto corporativo e levantar alternativas para desenvolvêlas.

Para Chiavenato (2012) "o empreendedor consegue fazer as coisas acontecerem por ser dotado de sensibilidade para os negócios, tino financeiro e capacidade de identificar e aproveitar oportunidades, nem sempre claras e definidas." Fazer com que as coisas aconteçam é uma necessidade contínua para evolução da economia e do status quo social. A criatividade e inovação, características básicas para resolução de problemas e para o empreendedorismo, são peças fundamentas na engrenagem do progresso.

A escolha da temática se deu pelo desejo dos autores em poder contribuir com o desenvolvimento de pessoas que estão estagnadas no mercado ou desistem diante de desafios impostos em suas jornadas, a buscar a realização profissional.

Chiavenato (2012) ainda descreve que "o transforma ideias em realidade para benefício próprio e para o benefício da sociedade e da comunidade." Discorre ainda que "por ter criatividade e um alto nível de energia, o empreendedor demonstra imaginação e perseverança, aspectos que, combinados adequadamente, habilitam-no a transformar uma ideia simples em algo que produza resultados concretos e bem-sucedidos no mercado."

Diante desse contexto as competências empreendedoras ganham destaque, sendo um dos principais impulsionadores para que pessoas e famílias possam se reposicionar no mercado e manter suas rendas, e consequentemente a economia local, sendo esses fatores motivadores para a escolha da temática.

\section{IDENTIFICAÇÃO DA PROBLEMÁTICA}

Chiavenato (2012) afirma que a atividade do empreendedor é muitas vezes associada à incerteza, principalmente quando o seu negócio envolve algo realmente novo ou quando o mercado para o seu produto sequer existe. Knight (1967) classifica três tipos de incerteza:

- Risco: pode ser estatisticamente mensurável, como a probabilidade de sortear uma bola vermelha em uma jarra 
contendo cinco bolas vermelhas e cinco bolas brancas;

- Ambiguidade: quando é difícil de medir estatisticamente, como a probabilidade de sortear uma bola vermelha em uma jarra contendo cinco bolas vermelhas e um número desconhecido de bolas brancas;

- Incerteza: quando é impossível estimar ou predizer estatisticamente, como a probabilidade de sortear uma bola vermelha em uma jarra cujo número de bolas vermelhas é desconhecido, bem como o número de outras bolas coloridas.

O medo de se lançar às novas possibilidades e empreender ideias e soluções, seja trabalhando em empresas ou de forma autônoma, é um agravante para que as pessoas possam ter suas carreiras profissionais e condições de vida melhoradas.

Em e-Book divulgado pelo SEBRAE, uma das instituições que mais investem no empreendedorismo no país, é pontuado que a burocracia é um fator que desestimula o empreendedor. Para se abrir uma empresa muitas vezes são necessários, com necessidade de apresentação de vários documentos e custos elevados para a maioria das pessoas que pretendem ingressar na legalidade.

Outro ponto de destaque apresentado é que o custo médio de abertura de uma empresa no Brasil, considerando todas as etapas e taxas nos 27 estados, todos os portes e os setores de comércio, serviço e indústria é de $\mathrm{R} \$ 2.038$.

O e-Book apresenta ainda que não bastassem a burocracia e os elevados custos para a abertura das empresas, os empresários se veem assolados pelos mesmos problemas para a manutenção da empresa, principalmente por conta dos impostos. O Brasil apresenta uma taxa de encargos sociais de 91,8\%, ou seja, quase $\mathrm{R} \$ 1$ de obrigações pagos para cada $\mathrm{R} \$ 1$ de salário.

O SEBRAE pontua ações realizadas pelo Governo Federal como a instituição do MEI (Micro Empreendedor Individual) e o sistema Simples Nacional de tributação para empreendedores. Essas ações visam diminuir os índices de informalidade e aumentar o recolhimento de tributos.
Mesmo diante dessas possibilidades ainda é uma condição maior os medos diante novos desafios, o que exigem o desenvolvimento de algumas habilidades específicas para assumir riscos, que nem todos possuem. Chiavenato (2012) elenca que para ser bem-sucedido, o empreendedor precisa:

- Ter vontade de trabalhar duro;

- Ter habilidade de comunicação;

- Conhecer maneiras de organizar o trabalho;

- Ter orgulho daquilo que faz;

- Manter boas relações interpessoais:

- Ser um self-starter, um auto propulsionador;

- Assumir responsabilidades e desafios;

- Tomar decisões.

As responsabilidades exigidas e as variáveis de ser ter um negócio próprio, assim como assumir posicionamentos para solução de problemas nas empresas, fazem com que muitas pessoas optem por permanecerem em estado de inércia. Essa falta de atitude empreendedora faz com que a economia se desenvolva lentamente. Frente ao cenário da pandemia do COVD-19, se reinventar e buscar novas possibilidades é uma máxima para manutenção de negócios e empregos, emergindo ainda mais a necessidade das competências empreendedoras.

\section{COMPREENSÃO DA REALIDADE}

Ao analisar a relevância dos empreendedores para o contexto econômico Chiavenato considera:

Os empreendedores são heróis populares do mundo dos negócios. Fornecem empregos, introduzem inovações e incentivam o crescimento econômico da região ou do país. Não são simplesmente provedores de mercadorias, serviços, informação ou entretenimento, mas poderosas fontes de energia, que assumem riscos inerentes em uma economia em mudança, transformação e crescimento. CHIAVENATO (2012)

Assim sendo, e partindo da análise observada pelo comportamento de pessoas nas empresas em que os autores desse artigo trabalham, foi possível evidenciar situações de baixa auto 
responsabilidade, auto liderança e auto diretividade, além de baixa criatividade e envolvimento para resolução de problemas. Esses comportamentos são diretivos para 0 empreendedorismo, seja interno nas organizações ou para montar um negócio próprio.

Os aspectos observados foram evidenciados em narrativas em diálogos estruturados acerca da temática com demais membros das empresas e da comunidade acadêmica, em que se destacou que a falta de atitude pode influenciar na vida profissional, na tomada de decisão, e na realização de sonhos pessoais e profissionais das pessoas.

Em publicação realizada pelo site Exame.abril foi vinculada uma pesquisa feita pela empresa Brands2Life, em parceria com o LinkedIn, concluindo que $79 \%$ dos trabalhadores brasileiros não se candidatam a vaga de emprego que desejam. Segundo o estudo, o principal motivo (18\%) é o medo de que o novo trabalho seja pior que o atual. Os dados também mostram que quanto maior a idade, maior a relutância para se candidatar a uma vaga. Profissionais entre 18 e 34 anos que estão infelizes no emprego atual, tendem a demorar 8 meses para começar a pensar em sair, já aqueles que têm entre 45 e 54 anos demoram, em média, 20 meses.

As evidências publicadas pela Brans2Life vão ao encontro dos pontos observados pelos autores na realidade local das empresas da cidade de Araguari. Entende-se que esses padrões sociais são característicos de uma cultura social predominante que é disseminada e passada por gerações, em que é estimulada a busca pela estabilidade e menor esforço para resultados.

Dornelas (2018) nos apresenta que há ainda pessoas com conhecimento tácito (aquele que o indivíduo adquire ao longo da vida, fruto de sua experiência prática), mas pouco conhecimento explícito (o formal, que pode ser registrado e facilmente comunicado) que, por necessidade, começam a empreender, buscando o sustento para si e sua família. $O$ autor ainda apresenta que como empreender está ligado à ação, a pessoa deve atentar para os eventos que ocorrem em seu ambiente e que, em muitos casos, acabam por apresentar o empreendedorismo como um caminho óbvio para seu futuro.

Considerando as observações realizadas, as justificativas e a problemática sinalizada, foram levantados possíveis fatores imediatos e os condicionantes maiores, associados ao problema em questão.

\section{Possíveis fatores imediatos:}

- Idade: A idade influência diretamente nas escolhas profissionais do indivíduo, pois mais velho, o medo de arriscar aumenta consideravelmente;

- Estabilidade profissional: quanto mais tempo uma pessoa perdura em uma determinada profissão, mais medo ela tem de enfrentar novos desafios.

\section{Possíveis condicionantes maiores:}

- Situação econômica do país: Quando o país enfrenta uma crise econômica, cria certa instabilidade no mercado de trabalho, logo as empresas diminuem as contratações, gerando medo e receio de buscar outra oportunidade profissional;

- Situação financeira familiar: Se o indivíduo é o único provedor de receita na família, a decisão de mudar profissionalmente pesa mais.

A reflexão sobre os fatores imediatos e os condicionantes maiores, associados ao problema, culminam em alguns aspectos essenciais ou pontoschave:

- Atitude empreendedora;

- Carreira profissional impulsionada pelo empreendedorismo;

- Intraempreendedorismo;

- Empreendedorismo emergente.

\section{O EMPREENDEDORISMO NO BRASIL}

Buscou-se uma fundamentação teórica que nos propiciasse um maior embasamento a respeito dos pontos-chave levantados e que, consequentemente, pudesse nos conduzir às hipóteses de solução para o problema eleito.

Esses aspectos foram objetos de uma busca feita em artigos de escritores reconhecidos na área de empreendimento e sites de artigo de administração. 
De acordo com artigo vinculado em 15 de fevereiro de 2020 pelo site Exame.abril, 19 estados brasileiros e o Distrito Federal registraram recorde na quantidade de trabalhadores sem carteira assinada e a taxa de informalidade aumenta e é a maior desde 2016. A fonte de pesquisa para essa publicação foram pesquisas realizadas pelo IBGE e comprovam que há aumentos consideráveis na busca por rendas paralelas, visto que o cenário de empregabilidade não é favorável no país.

Segundo estudo feito pelo monitoramento de empreendedorismo global (GEM - Global Entrepreneurship Monitor) juntamente com o SEBRAE, o Brasil, no ano de 2020, "deve atingir o maior patamar de empreendedores iniciais dos últimos 20 anos, com aproximadamente $25 \%$ da população adulta envolvida na abertura de um novo negócio ou com um negócio com até 3,5 anos de atividade."

Entende-se que as pessoas estão sendo cada vez mais enfrentando a competitividade do empreendedorismo, e até mesmo sendo motivada por campanhas (MEl, pequeno $e$ microempreendedores) criadas nos últimos anos que reduzem os custos fiscais, a burocracia e incentivam a abertura do próprio negócio.

\section{ATITUDE EMPREENDEDORA}

As habilidades requeridas de um empreendedor podem ser classificadas em áreas: técnicas, gerenciais e características pessoais. As características pessoais podem incluir: ser disciplinado, assumir riscos, ser inovador, ser orientados para as mudanças, ser persistente e ser um líder visionário. (DORNELAS, 2001).

Todas as pessoas possuem, em maior ou menor grau características empreendedoras, porém nem sempre sabem colocar em prática ou até mesmo cultivá-las. Geralmente isso ocorre por falta de atitude, nesse caso a atitude precisa ser reformulada para elevar seu grau pessoal de realizações.

A atitude leva a imaginar uma ação, uma postura ativa na direção de colocar algo em andamento, e está muito associada a fazer acontecer. É possível dizer que uma pessoa que tenha uma atitude proativa em relação a determinado objetivo seria capaz de buscar o conhecimento e a habilidade necessária para tal" (...) O comportamento tem uma diferença em relação à atitude, pois é algo essencialmente racional, decorrente do conhecimento, da habilidade e das percepções. Mas, sendo o comportamento uma posição racional, não necessariamente conduz um indivíduo a agir sempre e de maneira determinada seguindo sua racionalidade. (SALIM e SILVA, 2010)

\section{CARREIRA PROFISSIONAL IMPULSIONADA PELO EMPREENDEDORISMO}

Aparentemente as pessoas poderiam ter bons conhecimentos sobre 0 assunto, pois 0 planejamento de carreira é tema de grande interesse nos dias de hoje. Na TV, no rádio, nos jornais e revistas, nos livros, na internet, em palestras com os mais variados enfoques, vamos encontrar uma significativa massa de informação sobre desempenho, carreira e sucesso. Há orientação para os profissionais em início de carreira, para aqueles que já caminharam alguns anos e para aqueles que estão próximos da aposentadoria. (ROSA, 2011)

De acordo com estudos feitos pela Catho online, um dos fatores determinantes da evolução no empreendedorismo quanto a carreira profissional, seria a auto liderança, e alguns consultores da Catho indicam 6 passos para estimular a auto liderança, que são: Assumir a responsabilidades, buscar o autoconhecimento, suportar julgamentos, conheça o lugar onde trabalha, conheça seus colegas de trabalho e caso já seja um líder, demonstre confirma aos seus funcionários, acompanhar resultados, criticar nos momentos certos, buscando sempre o desenvolvimento de sua equipe.

Muitos são os casos de pessoas que sonham em empreender e que trabalham a vida toda como empregada, adquirindo conhecimento e habilidade para cooperar em determinada empresa e que mais tarde utiliza todo esse conhecimento para abrir seu próprio negócio e acaba virando um grande sucesso, e vice versa.

É necessário ter em mente, o quanto é difícil construir uma carreira profissional de sucesso, sabendo que durante todo esse ciclo, irá passar por algumas dificuldades, tanto com questões 
emocionais e psicológicas, quanto com problemas de saúde, entre outros. Em alguns momentos é preciso, para que possa ver outras áreas de atuação, sempre absorvendo conhecimento, e saber aplicálas na sua própria carreira.

\section{INTRAEMPREENDEDORISMO E EMPREENDEDORISMO EMERGENTE}

O primeiro a falar sobre intraempreendedorismo foi Gifford Pinchot III, em seu livro "Intrapreuner" de 1985, que diz "O intraempreendedorismo (intrapreneuring) é um sistema para acelerar as inovações dentro de grandes empresas, através do uso melhor dos seus talentos empreendedores. Portanto, significa uma maneira saudável para haver positivas reações aos desafios empresariais do novo milênio."

No atual momento, são poucas as pessoas que têm atitude, e o que as empresas precisam são de intraempreendedores para solucionar seus problemas e tomar a frente.

$\mathrm{O}$ autor Gifford Pinchot III destaca também seus 10 mandamentos sobre intraempreendedorismo que são eles:

1. Vá trabalhar todos os dias disposto a fazer o melhor que puder;

2. Negar-se a executar as ordens recebidas faz seus objetivos pararem;

3. Faça todo e qualquer trabalho necessário, independentemente de ser sua função;

4. Encontre pessoas para ajudá-lo;

5. Siga sua intuição sobre as pessoas que você escolher e trabalhe com elas sempre para o melhor;

6. A publicidade aciona o sistema imunológico corporativo;

7. Nunca aposte em uma corrida a menos que você esteja participando dela;

8. É mais fácil pedir perdão que permissão;

9. Seja fiel ao seu objetivo e realista sobre os caminhos para alcançá-lo;

10. Honre seus líderes.
Seguindo os mandamentos, a caminhada para o sucesso começa sempre pensando fora da caixa, tendo a oportunidade de fazer diferenças significativas em sua empresa.

Diante dessa pandemia, evidencia-se que os empreendedores sofrem bastante a partir do momento em que estão de portas fechadas. Logo, são nesses momentos que surge uma palavra como destaque: A inovação. São pessoas buscando novas formas de empreender, seja pelo delivery, seja através do e-commerce. É um momento emergente de ideais, e formas de reinventar e readaptar diante desse imprevisto.

(...) A relação entre empreendedorismo e
desenvolvimento econômico é
representada pela inovação, seja pela
criação de novos produtos ou serviços seja
pela forma diferente de fornecê-los; pelo
desenvolvimento tecnológico e pela
capacidade de gerar novos empregos
estimulando o mercado de trabalho.
(FESTINALLI, 2003)

Assim, a inovação está diretamente ligada ao empreendedorismo, e se destaca principalmente em momentos de crise, fazendo com que surjam novas formas de se comercializar produtos, ou até mesmo começar um novo empreendimento.

\section{HIPÓTESES DE SOLUÇÃO DO PROBLEMA}

A reflexão dos aspectos desenvolvidos na pesquisa realizada com base na literatura, principalmente de Chiavenato, Menezes e Dornelas, aqui explorada, possibilitou apresentar diversas alternativas que contribuem para a solução do problema estudado, como:

- Treinamento para estimular a autoconfiança;

- Buscar conhecimentos através de cursos;

- Oportunidade de abrir seu próprio negócio;

- Criação de um aplicativo;

- Campanha motivacional para desenvolver habilidades intraempreendedoras. 
Diante das alternativas apresentadas, entende-se que todas são de extrema importância para o aumento do conhecimento e encorajamento diante das oportunidades de se empreender.

\section{APLICAÇÃO À REALIDADE}

De acordo com as informações levantadas e apresentadas, entende-se o quanto é importante sempre buscar estudos feitos por grandes escritores, acompanhar estatísticas e ter por perto cases de sucesso para aplicações em sua empresa.

Em virtude da pandemia da COVID-19 as pessoas tiveram que se adaptar e buscar novas maneiras de se desenvolver já que o isolamento social é necessário. Sugere-se aqui uma possibilidade de aplicação a ser realizada através de cursos para buscar ou aprimorar conhecimentos e habilidades.

Planeja-se a utilização do site do SEBRAE, em que contém uma variedade de cursos gratuitos e de curta duração, por exemplo:

- Aprenda a planejar as estratégias do seu negócio

- Como vender pela internet

- Como expandir seu negócio

- Planejamento estratégico para Empreendedores

- Empreendedorismo como opção de carreira

Com isso pode-se incentivar o aprendizado suficiente para começar a empreender e intraeemprender tendo uma melhor noção do mercado externo tanto quanto as aplicações internas na empresa.

\section{CONSIDERAÇÕES FINAIS}

Ao decorre da criação desse artigo, a busca foi sempre assumir o compromisso em prestar um auxílio as pessoas que tem dificuldade em empreender, que por muitas vezes é causado por falta de conhecimento e/ou atitude.

Por toda a extensão desse artigo alguns autores foram usados como base de estudos, entre eles Chiavenato, Mendez e Dornelas, possibilitando o debate entre possíveis fatores condicionantes maiores e fatores imediatos que influenciam no empreendedorismo emergente ou intraempreendedorismo.

O entendimento da importância das competências empreendedoras fica evidentes no decorrer dos assuntos apresentados, ressaltando a relevância para a constituição de uma cultura de protagonismo frente à problemas nas empresas. Destacam-se as habilidades intraempreendedoras, entre as quais estão criatividade e inovação, como fatores para sucesso da empreitada de carreiras promissoras e resultados positivos das organizações.

Compreende-se que a busca por conhecimento depende do próprio individuo, por isso indica-se a utilização do site do SEBRAE que oferece um grande suporte, e uma série de ferramentas, cursos e treinamentos para adquirir esse conhecimento.

\section{REFERÊNCIAS}

6 passos para estimular a auto liderança. Portal Catho, 2018. Disponível em:

https://www.catho.com.br/carreirasucesso/carreira/dicas-emprego/6-passos-paraestimular-a-autolideranca/. Acesso em: 13 jun. 2020.

Brasil deve atingir marca histórica de empreendedorismo em 2020. Agência Sebrae, 2020. Disponível em:

http://www.agenciasebrae.com.br/sites/asn/uf/NA brasil-deve-atingir-marca-historica-deempreendedorismo-em2020,d9c76d10f3e92710VgnVCM1000004c00210a RCRD. Acesso em: 11 jun. 2020.

CHIAVENATO, Idalberto. Empreendedorismo: Dando Asas ao Espírito Empreendedor. 4. Ed. Barueri, SP: Manole, 2012.

DORNELAS, José. Introdução ao empreendedorismo - Desenvolvendo habilidades para fazer acontecer. São Paulo: Empreende, 2018.

FESTINALLI, Rosane Calgaro. Estratégias empresariais em empresas do contexto empreendedor: o caso da indústria laticínio vila nova. In: ENCONTRO DE ESTUDOS ESTRATÉGICOS DA ASSOCIAÇÃO NACIONAL DOS PROGRAMAS DE 
PÓS- Francisco Sávio de Oliveira Barros, João Luis Alexandre Fiúsa \& Ana Silvia Rocha Ipiranga REAd Edição 47 Vol. 11 No. 5, set-out 200527 GRADUAÇÃO EM ADMINISTRAÇÃO - 3Es, I, 2003, Curitiba-PR. Anais...Curitiba: ANPAD, 2003, 1 CD ROM.

Formalização: o caminho para o crescimento do Microempreendedor Individual. Agência Sebrae, 2019. Disponível em:

https://www.yumpu.com/pt/document/read/2283 3607/formalizacao-o-caminho-para-o-crescimentodo-microempreendedor-individual. Acesso em: 28 abr. 2020.

GARTNER; W. B. What are we talking when we talk about entrepren- eurship? Journal of Business Venturing, v. 5, n. 1, p. 15-28, jan. 1990.

GRANATO, Luísa. A maioria dos brasileiros perde oportunidades de emprego por esta razão.

Disponível em:

https://exame.abril.com.br/carreira/a-maioria-dosbrasileiros-perde-oportunidades-de-emprego-poresta-razao/. Acesso em: 29 abr. 2020.

LONGENECKER, J. G.; MOORE, C. W.; PETTY, W. J. Administração de pequenas empresas. São Paulo: Makron Books, 1998.

ROSA, José Antônio. Carreira: planejamento e gestão. São Paulo: Cengage Learning, 2011.

SALIM, Cesar Simões; SILVA, Nelson Caldas. Introdução ao empreendedorismo: Despertando a atitude empreendedora. Editora Campus, 2010.

Taxa de informalidade aumenta e é a maior desde 2016. Estadão Conteúdo, 2019. Disponível em: https://exame.abril.com.br/economia/taxa-deinformalidade-aumenta-e-e-a-maior-desde-2016/. Acesso em: 28 abr. 2020.

WRIGHT, James Terence Coulter; SILVA, Antonio Thiago Benedete; SPERS, Renata Giovinazzo. 0 mercado de trabalho no futuro: uma discussão sobre profissões inovadoras, empreendedorismo e tendências para 2020. RAI-Revista de Administração e Inovação, v. 7, n. 3, p. 174-197, 2010 . 